\title{
Raça, cor, cor da pele e etnia
}

\author{
Antonio Sérgio Alfredo Guimarấes
}

Nas ciências sociais brasileiras, a raça já sofreu algumas reviravoltas, exemplificando melhor que outros, talvez, as vicissitudes políticas das noçôes e conceitos científicos. No Brasil, ela foi introduzida pela geração de 1870 , que tomando-a emprestada das ciências naturais da época, procurava dar uma orientação científica aos estudos sobre a cultura brasileira, propondo, ao mesmo tempo, um programa de desenvolvimento político para a nação pós-escravista (Skidmore 1974, Ventura 1991, Schwarcz 1993). Seguia assim, grosso modo, a orientação que havia sido dada por von Martius em seu célebre opúsculo de 1845 (Rodrigues e von Martius 1956).

Para esta geração, o conceito de raça, tal qual fora utilizado pela biologia do século XIX, era empregado para explicar as diferenças culturais entre os povos e o modo subordinado com que foram incorporados ao sistema mercantil global pela expansão e conquista européias. Para ser claro: abstraía-se da história e das formas sociais, econômicas e culturais para reduzir a desigualdades de situação entre os povos a caracteres físicos e biológicos. No entanto, se é certo, como apontou Manoel Bonfim (1993), em seu tempo, que a teoria racial tinha uma motivação claramente imperialista; no Brasil, os nossos cientistas introduziram à teoria das raças uma motivação política própria: a nova nação, como ensinara von Martius, seria o resultado do entrecruzamento entre três raças (a caucasoide, a africana e a americana) mas tal produto resultaria num povo homogêneo, de cultura latina. Tal processo de miscigenação, potencializado pelo estímulo à novas ondas imigratórias de povos europeus, ficou conhecido como embranquecimento.

Longe de ser simples especulação de intelectuais, a mestiçagem e o embranquecimento, como processos que dotariam a jovem naçáo brasileira de uma base demográfica homogênea, se firmaram como verdadeiras políticas raciais no Brasil (Park 1942), mesmo quando o conceito de raça e as teorias que a utilizavam caíram em total descrédito no mundo científico e intelectual. Apenas para exemplificar o que digo: a revolução de 1930 e, posteriormente o Estado Novo, assim como a Segunda República brasileira, dotarão a nação de uma política cultural explicitamente baseada nesses dois pilares - mestiçagem e hegemonia da língua e das tradiçóes portuguesas e latinas. $\mathrm{O}$ desenvolvimento capitalista brasileiro, depois de 1930, se fará procurando homogeneizar mercados nacionais (de capitais, de circulação de mercadorias e de trabalho), facilitando também a homogeneização cultural e racial. Entre 1940 e 1970, regióes como o Norte e o Nordeste (ou alguns bolsóes do Sudeste) em que um quarto da população se autodeclarava branca, serão os grandes celeiros de máo-de-obra para o Sul e o Sudeste, onde fora maior o impacto da grande imigração européia, que se declarava branca.

É nesse período que ocorre o banimento do termo raça de nosso vocabulário científico, político e social, como consequência não apenas dos processos a que acabo de me referir, mas também por conta das tragédias causadas pelo racismo em termos mundiais, cujas principais expressôes foram o Holocausto, na Segunda Guerra Mundial; a segregação racial nos Estados 
Unidos, que perdurou no pós-guerra; e o apartheid, na África do Sul, até bem recentemente.

Como se explica, então, o retorno da raça à nossa linguagem atual? $\mathrm{O}$ termo é tão presente, inclusive no cotidiano, que o IBGE o introduziu nos censos demográficos em 1991, transformando a antiga pergunta "Qual é a sua cor?” em "Qual é a sua cor/raça?". Temos que reconhecer, primeiro, que o termo não havia desaparecido de todo, passando mais por uma submersão que um desaparecimento. Em primeiro lugar, a expressão que passou a definir o nosso ideal de homogeneidade nacional, nosso hibridismo demográfico e o reconhecimento da importância cultural de todos os povos para a nossa formação foi o de democracia racial. Em segundo lugar, no uso burocrático e popular, o termo cor substitui o de raça, mas deixou à mostra todos elementos das teorias racistas cor, no Brasil, é mais que cor de pele: na nossa classificaçáo, a textura do cabelo e o formato de nariz e lábios, além de traços culturais, são elementos importantes na definição de cor (preto, pardo, amarelo e branco). Terceiro, o termo etnia, cunhado para dar conta da diversidade cultural humana, passou também a ser usado no cotidiano das sociologias vulgares como marcador de diferenças quase-irredutíveis, ou seja, como sinônimo de raça. Suprimia-se o termo raça sem que o processo social de marcação de diferenças e fronteiras entre grupos humanos perdesse o seu caráter reducionista e naturalizador.

Mas, o mais importante para o ressurgimento da raça, enquanto classificador social, se deu com sinal invertido, isto é, como estratégia política para incluir, não para excluir, de reivindicar e não de sujeitar. São os movimentos sociais de jovens pretos, pardos e mestiços, profissionais liberais e estudantes, que retomaram o termo, para afirmar-se em sua integridade corpórea e espiritual contra as diversas formas de desigualdade de tratamento e de oportuni- dades a que estavam sujeitos no Brasil moderno, apesar - e talvez pour cause - da democracia racial. Os movimentos sociais a que me refiro têm trajetória longa na história brasileira, desde as sociedades e jornais de homens de cor, no começo do século XX, passando pelo o Movimento Negro Unificado, dos anos 1970, até as ONGS negras dos nossos dias.

A raça retorna, portanto, não mais como mote do imperialismo ou colonialismo, mas como glosa dos subordinados ao modo inferiorizado e desigual com são geralmente incluídos e tratados os negros, as pessoas de cor, os pardos. Para os cientistas sociais, assim como para os ativistas políticos, a noção de raça tem vantagens estratégicas visíveis sobre aquela de etnia: remete imediatamente a uma história de opressão, desumanização e opróbio a que estiveram sujeitos os povos conquistados; ademais, no processo de mestiçagem e hibridismo que sofreram ao logo dos anos, a identidade étnica dos negros (sua origem, seus marcadores culturais, etc.) era relativamente fraca ante os marcadores físicos utilizados pelo discurso racial.

Renascido na luta política, a noção é recuperada pela sociologia contemporânea como conceito nominalista - isto é, para expressar algo que não existindo, de fato, no mundo físico, tem realidade social efetiva (Guimarães 1999). Sem ele, ficaria impossível explicar a longa trajetória que culmina na mobilização de símbolos, temas e repertórios dos movimentos sociais contemporâneos. Raça, enquanto conceito analítico, permite, por exemplo, examinar a acusação feita por alguns antropólogos (Maggie 2005) segundo a qual a insistência do movimento negro atual em classificar como negros aqueles que se declaram nos censos pardos e pretos seria uma atitude anti-modernista de retomar um racialismo que marcara brevemente os intelectuais naturalistas da geração dos 1870. No restante desse breve artigo procurarei demonstrar como o nosso sistema de classifi- 
cação por cor náo se sustenta sem o recurso sub-reptício à noção de raça e à teoria do embranquecimento.

Para começar, lembro que chamar de antimodernista a atitude do movimento negro seria apropriado apenas para se referir à Frente Negra Brasileira dos anos 1930. De fato, àquela época, enquanto em São Paulo os negros se mobilizavam politicamente em torno da identidade racial negra, aproveitando o clima geral de racialização da política que soprava da Europa, aqui mesmo, e em todo o Brasil, os intelectuais modernistas e regionalistas, muitos deles mestiços, gestavam a reinvenção da nacionalidade brasileira em torno do ideal da mistura de raças. Há que se lembrar que este ideal de mestiçagem e hibridismo é algo vem de tempo mais recuado, já captado por Von Martius em seu célebre opúsculo Como escrever a história do Brasil. Certamente, a descoberta de que a nação brasileira tinha um povo mestiço data da campanha abolicionista. Releiam Nabuco, em $O$ erro do imperador, e encontrarão lá, com todas as letras:

Os nobres e aristocráticos adversários do sr. Dantas, descendentes quase todos de senhores de engenho e fazendeiros, quando chegavam às janelas da Câmara e viam uma dessas manifestaçóes populares, não descobrindo chapéus altos nem sobrecasacas, mas, num relance, pés no chão e mangas de camisa, diziam somente: "Aquilo não vale nada, é a canalha”. Talvez, mas o nosso povo é isso mesmo, é um povo de pés no chão e mangas de camisa, e não é um povo branco.

Que a opinião de Nabuco, corrente entre abolicionistas negros, não era, até os anos 1930, inteiramente partilhada nos meios acadêmicos basta lembrar o seu conterrâneo Oliveira Lima, divido entre considerar se compunham o povo "os fazendeiros" ou apenas a ralé, o "povo propriamente":
No Brazil, como em toda a America Hispanica, faltava povo. Num dos seus officios para a chancellaria anstriaca o encarregado de negocios Mareschal observa que mesmo que o paíz viesse a soffrer dos horrores da revoluçáo, "o povo se cançaria da anarchia mais cedo do que na Europa, porque elle se compunha na sua totalidade de fazendeiros e não havia a ralé que se torna nas mãos dos agitadores cégo instrumento". A ralé existia, mas era um elemento inteiramente fóra da vida politica: o gráo de ignorancia, a condição de falta de cultura, vedava ao povo propriamente qualquer participação na vida consciente da communidade.

Pois, bem, já mostrei em Racismo e Anti-racismo no Brasil que o nosso sistema de classificação de cor se origina da intrincada teoria de embranquecimento que a nossa geração naturalista moldou a partir das diversas teorias raciais então vigentes. Esta origem está explicitada por Oliveira Vianna (1959 [1932]: 45). Nesta teoria, cor não é redutível a "cor da pele", a simples tonalidade. Cor é apenas um, o principal certamente, dos traços físicos - junto com o cabelo, nariz e lábios - que junto com traços culturais - "boas maneiras", domínio da cultura europeia, formavam um gradiente evolutivo de embranquecimento. Preto, pardo, branco. No grupo branco nunca se hesitaria em classificar alguém de pele escura, mas traços finos (europeus) e boa educação. Entre os pardos, estavam certamente aqueles de traços físicos "negróides", mas claros e bem educados.

É este sistema de classificação racial por cor - mas náo por cor da pele - que vem sendo paulatinamente modificado no Brasil, à medida que o ideal de embranquecimento vai perdendo força. De um lado, a organização política dos negros, que rejeita frontalmente o embranquecimento, e tenta impor uma noção histórica, política ou étnica de raça. Quando se remete à história, a noção reúne pessoas que 
vivenciaram uma experiência comum de opressão; quando se remete à política, cria uma associação em torno de reivindicaçóes; quando, se remete à etnia, quer criar um sentimento de comunidade a partir da cultura. Em todos os casos, os gradientes de cor seriam contraprodutivos, se não fossem reagrupados para tornar pretos e pardos uma única categoria discreta (não-contínua), que bem poderia ser batizada de afrodescendentes ou negros.

Do outro lado, a cor vem sendo substituída pela cor da pele, como princípio classificatório. Nesse modo de classificar, vigente na Europa atual, e muito utilizada no senso comum jornalístico, mesmo nos Estados Unidos, a cor da pele seria apenas o único critério na classificação. Ou seja, alguns brancos poderiam ser chamados de morenos, dark, foncés, brown, sem serem negros. Porque tal forma de classificar estaria se expandindo entre nós, no Brasil? Seria puro efeito da intensidade de nossos contatos com a Europa e os Estados Unidos?

Observando mais de perto essa forma de classificar, alguns fatos sobressaem. Primeiro, geralmente o termo branco é etnicizado para significar o europeu "de berço", ou seja, sem origem colonial ou imigrante de fora da Europa. Segundo, tal classificação parece conviver com outras classificações nativas. Por exemplo, Obama continua a ser referido como negro na Europa e no Brasil, pelo fato de ser negro nos Estados Unidos; ou um capoeirista mestiço brasileiro é negro também na Europa, pois é portador da cultura africano-brasileira. Terceiro, tal classificação não se aplica a povos orientais, como chineses, japoneses ou coreanos. A cor da pele se refere a um gradiente entre branco e preto.

Podemos concluir, provisoriamente, que esta forma de classificar é ainda menos consistente que a anterior, que levava em consideração outros traços físicos, além da cor da pele, possibilitando um gradiente mais extenso. Uma outra conclusão, aparentemente parado- xal, é que, apesar de mais fluída no gradiente, a classificação por cor da pele discrimina melhor o grupo branco, ou seja, o distingue de todas as outras cores sem os riscos de confusão possibilitados pelo embranquecimento. Evita-se e nega-se formas raciais de classificação, entendendo que a tonalidade da pele é um dado natural. No entanto, pode-se muito bem, voltar-se a uma dicotomia antiga: brancos versus pessoas de cor.

Se assim é, porque tantas pessoas no Brasil insistem em falar em "cor da pele" ao invés de apenas em "cor", como é nossa tradição? De fato, pesquisa recente do IBGE (2008) mostra que a nossa forma tradicional de classificar encontra-se em plena vigência. $\mathrm{Na}$ tabela abaixo, pode-se ver que outros traços físicos, origem familiar, cultura e posição socioeconômica são igualmente mobilizados para definir a categoria censitária "cor/raça".

Tabela 1: Brasil, proporção de pessoas de 15 anos ou mais de idade, por dimensões pelas quais definem a própria cor ou raça, 2008

\begin{tabular}{|l|l|}
\hline Cor da pele & 82,3 \\
\hline Traços físicos & 57,7 \\
\hline Origem familiar, antepassados & 47,6 \\
\hline Cultura, tradição & 28,1 \\
\hline Origem sócio-econômica & 27,0 \\
\hline Opção política /ideológica & 4,0 \\
\hline Outra & 0,7 \\
\hline
\end{tabular}

Fonte: IBGE (2008)

Em plena vigência, mas modificado. Minha sugestão é que nosso sistema tradicional de classificação está sendo modificado pela perda de sentido do ideal de embranquecimento. Alguns outros fatos podem ser recolhidos para fortalecer tal linha de raciocínio. De fato, a partir do censo de 2000 a população branca começa a declinar mais que o esperado pelas tendências demográficas, enquanto a parda, a preta e a amarela voltam a crescer. Essas mu- 
danças sugerem, nitidamente, que está em curso um processo de reclassificação racial, posto que as tendências demográficas (fecundidade, mortalidade e migraçóes) não a explicam.

Talvez por isso a tabela 1 acima mereça ser inquirida de modo mais agressivo. Não estarão as influências da origem familiar e antepassados, da cultura e da tradição, totalmente em desacordo com o que ensinam os estudos dos anos 1960, realizados, entre outros, por Harris (1970), Azevedo (1953), Nogueira (1954), Sanjek (1971) e Wagley (1952)? Nesses, como vimos, apenas traços físicos e posição social importavam. Agora, segundo esta pesquisa do IBGE, cresce a importância de fatores que definem as etnias (origem e cultura).

Ademais, comparando dois surveys realizados pelo DataFolha, o primeiro em 1995 , e o segundo em 2008, as respostas às mesmas perguntas captam uma diminuição de $18 \%$ no número de pessoas que se declaram espontaneamente brancas e um aumento de 18\% dos que se declaram morenas ou morenas claras (ver Tabela 2). Poderiam estes dados serem interpretados como uma renúncia à brancura por parte daqueles "brancos" de cor mais escura, aqueles que se consideram espontaneamente morenos? É o que sugiro. Tal renúncia não poderia ser feita se fatores outros como origem familiar (seus antepassados), ou sua tradição cultural, não ganhassem importância, na construção da identidade racial de cor, sobre ideais de embranquecimento.

Tabela 2: Declaração de cor espontânea em 1995 e 2008 (em \%)

\begin{tabular}{|l|l|l|l|}
\hline Qual a sua cor? & 1995 & 2008 & D \\
\hline Branca & 50 & 32 & -18 \\
\hline Moreno & 13 & 28 & 15 \\
\hline Parda & 20 & 17 & -3 \\
\hline Negro & 7 & 7 & 0 \\
\hline Moreno claro & 2 & 5 & 3 \\
\hline Preta & 1 & 4 & 3 \\
\hline
\end{tabular}

\begin{tabular}{|l|l|l|l|}
\hline Amarela & 1 & 2 & 1 \\
\hline Mulato & 1 & 1 & 0 \\
\hline Clara & 0 & 1 & 1 \\
\hline Outras & 1 & 3 & 2 \\
\hline Não sabe & 4 & 1 & -3 \\
\hline Total em \% & 100 & 100 & 0 \\
\hline
\end{tabular}

Fonte: DataFolha

Ou seja, minha sugestão é de que a cor da pele pode estar se destacando entre os elementos considerados na nossa classificação, justamente porque o ideal de embranquecimento tem-se enfraquecido. Para dizer de outro modo: à medida que a ideologia do embranquecimento perde importância, também o sistema de classificação em tipos raciais, que considera traços físicos e posiçáo social, perde saliência. Do antigo sistema racial, a cor da pele passa, portanto, a destacar-se.

Há também que se levar em conta, para explicar a força que a cor da pele ganha na percepção das pessoas, que esta forma de classificação social (a que faz referência explícita apenas à cor da pele), não somente é corrente na Europa ocidental, como tem curso livre na nossa imprensa e na sua sociologia espontânea, tendo hoje o respaldo de cientistas sociais e geneticistas de renome. Assim, os intelectuais que assinam o manifesto "Cento e treze cidadãos anti-racistas contra as leis raciais "reafirmam a inexistência de raças humanas, mas ignoram a existência de grupos sociais de cor, para enfatizar apenas a variação individual da cor da pele, realidade objetiva e natural:

Raças humanas não existem. A genética comprovou que as diferenças icônicas das chamadas "raças" humanas são características físicas superficiais, que dependem de parcela ínfima dos 25 mil genes estimados do genoma humano. A cor da pele, uma adaptação evolutiva aos níveis de 
radiação ultravioleta vigentes em diferentes áreas do mundo, é expressa em menos de 10 genes!

Até mesmo na sociologia de língua inglesa, antes tão imbuída da realidade social das raças, esta teoria naturalista e individualista da cor tem seus defensores. Por exemplo, Michael Banton, um dos sociólogos ingleses mais destacados no campo da "relaçóes raciais", passa também a adotar a estratégia discursiva ${ }^{1}$ de que o antídoto ao racismo é a afirmação da "cor" como uma realidade natural, objetiva e individual, e descarta o uso político ou analítico da noção de raça, que seria apenas um produto da imposição de uma linha de cor.

Este exemplo mostra que não apenas "raça”, mas também "cor" e "cor da pele" podem ser usados no mesmo contexto carregado de ideologia e de política, podendo ser manipulados como conceitos naturais na luta anti-racista ou na impostura racista. Podem também servir de marcadores para um discurso de solidariedade e de sentimento de pertencimento comunitário, que é, ao fim e ao cabo, o que distingue o discurso étnico - a referência a uma origem comum - ou nacionalista - de compartilhamento de um mesmo destino societário e político.

No caso da identidade negra, no Brasil, vários marcadores já foram utilizados pelo discurso mobilizador - lembrem-se que, segundo Barthes (1994), a formação étnica é também um empreendimento político -: a cor (as pessoas de cor), a raça (raça negra) e a posição social ("o negro é um lugar” como dizia Guerreiro Ramos (1995)). Sem dúvida, as duas primeiras formas de mobilização, apesar de imprecisas e incorretas cientificamente, foram as mais eficazes. Infelizmente, etnias, raças e cores humanas revelam-se refratárias às formas de esclarecimento pela razão. É como se fosse impossível ao ser humano, não apenas fugir à sociedade, mas ultrapassar formas de solidariedades grupais mais estreitas. As utopias individualistas, como lembrava Marx, são invenções possíveis apenas em sociedades complexas, formadas por classes sociais e outras formas de pertenças elementares.

\section{Notas}

1. O artigo, no prelo, aparecerá em breve no Ethnic and Racial Studies.

\section{Referências bibliográficas}

AZEVEDO, Thales de. Les Élites de couleur dans une ville brésilienne. Paris: UNESCO, 1953.

BARTH, Frederik. "Enduring and emerging issues in the analysis ofethnicity". In: VERMEULEN, Hans; GOVERS, Cora (Ed.). The anthropology of ethnicity, beyond ethnic groups and boundaries. Amsterdam: Het Spinhuis, 1994, p. 11-32.

BOMFIM, Manoel. América Latina: Males de Origem. Rio de Janeiro: Topbooks, 1993.

GUIMARÃES, Antonio Sergio A. (1999). Racismo e Anti-Racismo no Brasil, São Paulo, Ed. 34.

HARRIS, Marvin. Referential Ambiguity in the Calculus of Brazilian Racial Identity. Southwestern Journal of Anthropology, Vol. 26, n. 1 (Spring, 1970), p. 1-14, 1970.

IBGE, Diretoria de Pesquisas, Coordenaçáo de População e Indicadores Sociais, Pesquisa das Características Étnico-raciais da População 2008.

LIMA, Oliveira. O movimento da independência, 18211822. S. Paulo, Comp. melhoramentos de S. Paulo, Weiszfolg irmāos incorporado, 1922.

MAGGIE, Yvonne. Mário de Andrade ainda vive? O ideário modernista em questão, $R B C S$ vol. 20 n. 58 junho, p. 5-25, 2005.

NABUCO, Joaquim. "O erro do imperador" In: MELLO, Evaldo Cabral de (org.) Essencial Joaquim Nabuco. Penguin / Companhia das Letras, 2010.

NOGUEIRA, Oracy. "Preconceito racial de marca e preconceito racial de origem: sugestáo de um quadro de referência para a interpretaçáo do material sobre relaçôes raciais no Brasil". In: Tanto preto quanto branco: estudos de relaçôes raciais. São Paulo: T.A. Queiroz, (1985 [1954]), 67-93.

PARK, Robert. The Career of the Africans in Brazil, In- 
troduction to Donald Pierson, Negroes in Brazil. Chicago: University of Chicago Press, 1942.

RAMOS, Alberto Guerreiro. Introdução Crítica à Sociologia Brasileira, Rio de Janeiro, Ed. UFRJ, 1995.

SANJEK, R. Brazilian Racial Terms: Some Aspects of Meaning and Learning. American Anthropologist 73, p. 112-643, 1971.

SCHWARCZ, L. K. M. O Espetáculo das Raças, São Paulo, Cia das Letras, 1993.

VENTURA, Roberto. Estilo Tropical - História cultural e polêmicas literárias no Brasil, 1870-1914, São Paulo, Cia. Das Letras, 1991.
VIANNA, José de Oliveira. Raça e assimilação. Rio de Janeiro: J. Olympio, (1959 [1932]).

VON MARTIUS, Karl Friedrich e RODRIGUES, José Honório. Como se deve escrever a Historia do Brasil, Revista de Historia de América, n. 42, p. 433-458, dec., 1956.

WAGLEY, Charles. "Comment les classes ont remplacé les castes dans le Brésil septentrional”. In: WAGLEY, Charles (ed.). Races et Classes dans le Brésil Rural. Paris: UNESCO, 1952.

\section{autor \\ Antonio Sérgio Alfredo Guimarães \\ Professor do Departamento de Sociologia / USP}

Recebido em 15/09/2011

Aceito para publicação em 15/09/2011 